\title{
Avaliação morfológica da capacidade osteocondutora da hidroxiapatita implantada na calota craniana de camundongos diabéticos
}

\author{
Morphological study of the osteoconductive capacity of \\ hydroxyapatite implanted into the skull \\ of diabetic mice
}

\author{
Veronica Ozaki Gushiken ${ }^{1}$, Marcelo Rodrigues da Cunha ${ }^{2}$
}

Gushiken VO, Cunha MR. Avaliação morfológica da capacidade osteocondutora da hidroxiapatita implantada na calota craniana de camundongos diabéticos. Morphological study of the osteoconductive capacity of hydroxyapatite implanted into the skull of diabetic mice. Rev Med (São Paulo). 2013 jan.-mar.;92(1):75-7.

\begin{abstract}
RESUMO: Objetivo: Avaliar a capacidade osteogênica da hidroxiapatita quando implantada nos defeitos ósseos produzidos experimentalmente na calota craniana de camundongos NOD diabéticos. Materiais E Métodos: Utilizaram-se 10 camundongos NOD com $22 \mathrm{~g}$ e 20 semanas de idade. Os animais foram divididos em 2 grupos com 5 animais cada, sendo um grupo controle (não diabético) e outro diabético espontâneo. Criamos experimentalmente defeitos na calota craniana, através de uma broca cirúrgica, e preencheu-se com grânulos de hidroxiapatita. Após 4 semanas da cirurgia, os animais foram sacrificados e as amostras analisadas. $\mathrm{Na}$ radiologia, buscou-se analisar a radiopacidade do defeito ósseo e nas análises histológicas, a morfologia do tecido ósseo neoformado na área enxertada com a hidroxiapatita. A morfometria para quantificação do volume ósseo neoformado na área receptora do implante foi aplicada usando o método de estereologia de acordo com o princípio de DELESSE e os dados submetidos ao Teste de TUKEY pelo método ANOVA $(\mathrm{p}<0,0,5)$. Resultados: Nos resultados radiológicos tanto no grupo controle quanto no diabético, presenciou uma boa radiopacidade da hidroxiapatita, entretanto no grupo diabético ficaram mais evidentes pontos radiolucidos entre os seus grânulos indicando a infiltração de tecido conjuntivo. Quanto à microscopia, o osso neoformado projetou-se das extremidades da falha óssea em direção ao implante indicando uma boa interação osso-implante,
\end{abstract}

\begin{abstract}
Introduction: Diabetes mellitus is a worldwide public health problem that, if not treated adequately, can cause various diseases, including loss of bone mineral density as a characteristic manifestation of osteoporosis. In this condition, bone is more vulnerable to pathological fractures that can be treated by conventional clinical methods. However, depending on the severity and quantity of bone loss, implantation of biomaterial grafts such as hydroxyapatite is necessary. Clinical studies have demonstrated the biocompatibility and osteoconductive capacity of this material. Objectives: To evaluate the osteogenic capacity of hydroxyapatite implanted into bone defects experimentally induced in the skull of diabetic NOD mice. Methods: Fifteen NOD mice were divided into three groups: control (non-diabetic), spontaneously diabetic, and spontaneously diabetic receiving insulin replacement applied subcutaneously into the dorsum. Defects were created experimentally in the skull with a surgical bur and filled with porous hydroxyapatite granules. The animals were sacrificed 4 weeks after surgery and samples were obtained for analysis. Stereology was used to quantify the volume of newly formed bone in the recipient area according to the principle of Delesse. Data were analyzed by ANOVA followed by the Tukey test $(\mathrm{p}<0.05)$. Results: Radiology showed good radiopacity of the hydroxyapatite. However, radiolucent spots were seen between the hydroxyapatite granules in the diabetic groups, indicating infiltration of connective
\end{abstract}

\footnotetext{
$1^{\circ}$ lugar Prêmio Painéis Área Básica, XXXI Congresso Médico Universitário - COMU 2012.

Apoio: Laboratório de Morfologia do TEC - LTM FAPESP/FMJ. Departamento de Morfologia e Patologia Básica, Faculdade de Medicina de Jundiaí, Jundiaí, SP. NAPED/FMJ (Núcleo de Apoio à Pesquisa e a Docência da Faculdade de Medicina de Jundiaí). FAPESP (Fundação de Amparo à Pesquisa do Estado de São Paulo)

${ }^{1}$ Acadêmica do $5^{\circ}$ ano da Faculdade de Medicina de Jundiaí, Jundiaí, SP.

2. Professor Doutor da disciplina de Anatomia e Neuroanatomia da Faculdade de Medicina de Jundiaí, Jundiaí, SP.

Endereço para correspondência: Veronica O. Gushiken. Rua Rubens do Amaral, 626. CEP: 06070-210. Bairro Bela Vista, Osasco, SP. e-mail: veronica_ozaki@hotmail.com
} 
principalmente no grupo controle que teve um volume de osso formado de $46 \%$ sendo estatisticamente maior $(p<0,05)$ que o encontrado para o diabético (14\%). Sendo assim, a área receptora do grupo diabético apresentou com maior quantidade de tecido conjuntivo conforme ocorrido na imagem radiológica. Em ambos os grupos, o osso neoformado teve aspecto tanto de maturo com disposição cortical em alguns pontos quanto de imaturo em outros devido ao aspecto trabeculado e osteócitos desorganizados. Conclusão: A osteogênese conduzida pelas propriedades da hidroxiapatita pode ocorrer mesmo no tecido ósseo afetado pelos efeitos do diabetes, mas o volume de osso neoformado é menor e o processo osteoregenerador torna-se mais lento.

DESCRITORES: Camundongos endogâmicos NOD/cirurgia; Hidroxiapatias; Crânio/radiografia; Osteogênese.

\section{INTRODUÇÃO e OBJETIVO}

A diabetes mellitus quando não tratada adequadamente pode causar várias patologias, dentre elas destaca-se a diminuição da densidade mineral óssea com o quadro de osteoporose, tornando o tecido ósseo mais vulnerável às fraturas patológicas nas quais podem ser tratadas através dos métodos clínicos convencionais. Entretanto, dependendo da quantidade de perda óssea faz-se necessário a utilização de enxertos de biomateriais como a hidroxiapatita que vem se destacando em pesquisas clínicas devido a sua biocompatibilidade e capacidade osteocondutora. Entretanto, os resultados esperados podem ser comprometidos mediante aos efeitos deletérios do diabetes no metabolismo ósseo. Sendo assim, o objetivo deste trabalho foi avaliar a capacidade osteogênica da hidroxiapatita quando implantada nos defeitos ósseos produzidos experimentalmente na calota craniana de camundongos NOD diabéticos.

\section{MATERIAIS E MÉTODOS}

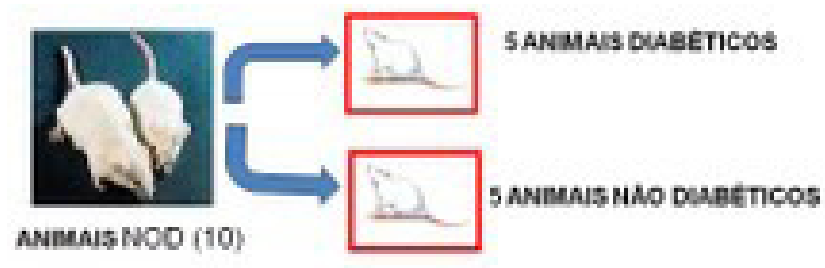

\section{Análise morfométrica}

Utilizou-se o método de esterelogia através da fórmula $\mathrm{VV}=\mathrm{PP} / \mathrm{PT}(\%)$. Os dados obtidos foram submetidos ao teste de Tukey pelo método ANOVA $(\mathrm{p}<0,05)$. tissue. Microscopy showed projection of newly formed bone from the margin of the bone defect toward the implant, a finding indicating good bone-implant interaction. The volume of newly formed bone was $46 \%$ in the control group and was significantly higher $(\mathrm{p}<0.05)$ than that observed in the diabetic group $(14 \%)$ and diabetic group receiving insulin (17\%). Thus, in the diabetic groups the recipient area contained a larger amount of connective tissue as demonstrated by radiology. In all groups, the defect was filled with partially mature (cortical arrangement) and partially immature bone (trabecular morphology and disorganized osteocytes). Conclusion: Osteogenesis guided by the properties of hydroxyapatite may even occur in bone suffering from the effects of diabetes, but the volume of newly formed is lower and the process is slower.

KEYWORDS: Mice, inbred NOD/surgery; Hydroxyapatites; Skill/radiography; Osteogenesis.

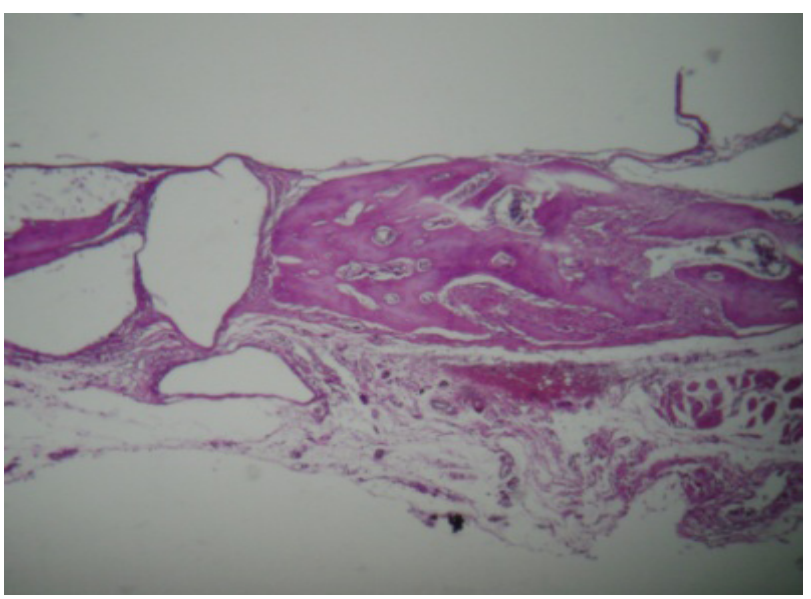

\section{Procedimento Cirúrgico}

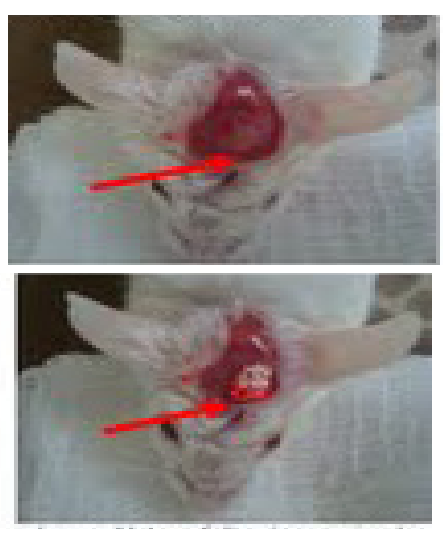

Vista superior da calota craniana do camundongo. Nota a falha óssea circular criada experimentalmente (seta) e em seguida preenchida com grânulos de hidroxiapatita (ha). 


\section{RESULTADOS}

\section{Resultados radiológicos}
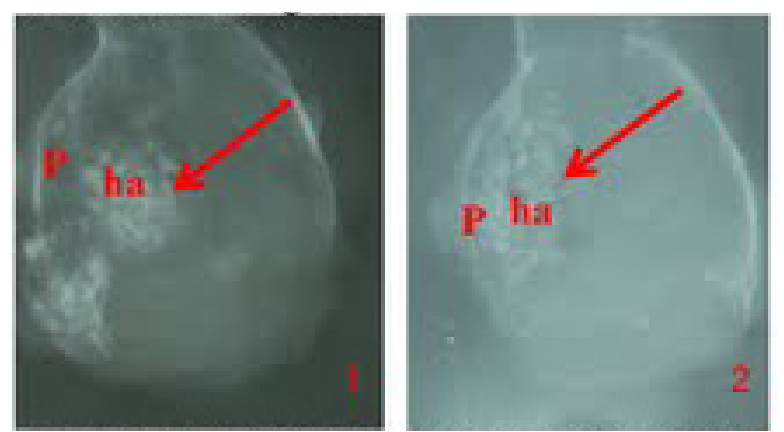

Figura 1 e 2. 1) Radiografias da calota craniana do grupo controle (não diabético). Nota-se o local da falha óssea (seta) no osso parietal (P) e os grânulos de hidroxiapatia (ha) em imagem radiopaca e condensada, concentrando-se na área receptora. Não houve migração dos gânglios para áreas distantes do local enxertado; 2) Radiografias da calota craniana do grupo diabético espontâneo. Verifica-se a localização nítida da área receptora e do biomaterial (seta). Destaca-se o espaçamento radiolúcido entre os grânulos da hidroxiapatia, sugestivo de infiltração de tecido conjuntivo. Indicados. Osso parietal (P) e grânulos de hidroxiapatita (ha).

\section{Resultados histológicos}
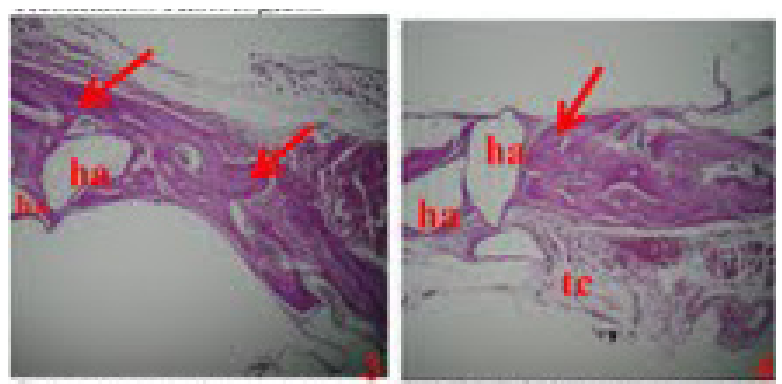

Figuras 3 e 4. Microscopia da área receptora do implante do grupo controle (não diabético). Evidencia-se o bom volume de osso neoformado (setas) a partir da margem do defeito criado experimentalmente e circundando os grânulos de hidroxiapatita (ha). Nota-se também osso jovem em disposição maturo em algumas partes e imaturas em outras. Indicados: Tc (tecido conjuntivo)
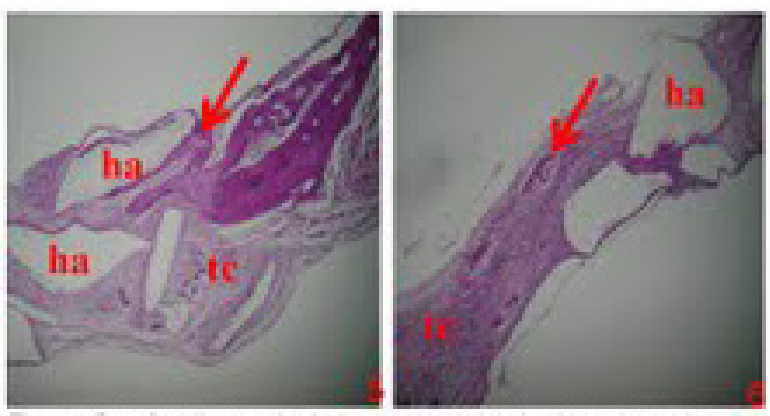

Figuras 5 e 6. Microscopia da área receptora do implante do grupo diabético. Evidencia-se a pouca neoformação óssea (setas) e abundante tecido conjuntivo (tc) circundando os grânulos de hidroxiapatita (ha)

\section{Resultados morfométricos}

Gráfico 1. Média do volume ósseo neoformado na área receptora da hidroxiapatita no grupo controle (não diabético) e diabético espontâneo. Nota-se valor significativamente $(\mathrm{P}<0,05)$ maior para o grupo controle em relação ao diabético

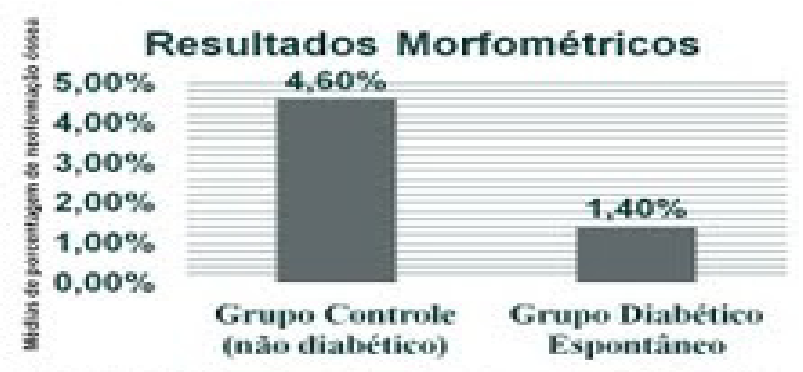

\section{CONCLUSÃO}

Os grânulos porosos de hidroxiapatita tem a capacidade de biocompatibilidade e osteocondutora mesmo implantados em tecido ósseo de camundongos diabéticos. Porém, a velocidade e a intensidade da neoformação óssea é menor no grupo diabético provavelmente pelos efeitos deletérios que o diabetes provoca no metabolismo ósseo e consequentemente, na osteogênese. 